\title{
Perioperative multiple low-dose Dexamethasones improves postoperative clinical outcomes after Total knee arthroplasty
}

Yuangang $\mathrm{Wu}^{1 \dagger}$, Xiaoxi $\mathrm{Lu}^{2,3+}$, Yimei Ma ${ }^{2,3}$, Yi Zeng ${ }^{1}$, Xianchao Bao ${ }^{1}$, Huazhang Xiong ${ }^{1}$ and Bin Shen ${ }^{1 *}$

\begin{abstract}
Background: The purpose of this study was to investigate the efficacy and safety of multiple low-dose dexamethasones in primary total knee arthroplasty (TKA).

Methods: One hundred fifty patients were equally randomized into 3 groups: Group A ( $n=50)$ received 2 doses of normal saline only; Group B $(n=50)$ received with 1 dose of intravenous dexamethasone and 1 dose of normal saline; Group C $(n=50)$ received with 2 doses of intravenous dexamethasone. The clinical outcomes and complications were assessed.
\end{abstract}

Results: The CRP and IL-6 were significantly lower in Group C and B than Group A at 24, 48, and $72 \mathrm{~h}$ postoperatively $(P<0.001$ for all). The intensity of postoperative nausea and vomiting (PONV) in Group C was lower than Group A at 24 $(P<0.001, P=0.002), 48(P=0.005, P=0.041)$ and $72 \mathrm{~h}(P=0.017, P=0.031)$ postoperatively and Group $B$ at $24 \mathrm{~h}(P=0.027$, $P=0.019)$ postoperatively. Pain were significantly less in Group $C$ than Group A at $24(P<0.001)$, $48 \mathrm{~h}(P=0.037)$ postoperatively and Group B $24 \mathrm{~h}(P=0.030)$ postoperatively. Patients in Group $C$ had better range of motion (ROM) and satisfaction than Group $A(P<0.001, P=0.002)$ and $B(P=0.001, P=0.043)$. No differences were found in complications.

Conclusions: The administration of $10 \mathrm{mg}$ dexamethasone $1 \mathrm{~h}$ before the surgery, and repeated at $6 \mathrm{~h}$ postoperatively can significantly reduce the level of postoperative CRP and IL-6 and the incidence of PONV, relieve pain, achieve an additional analgesic effect, and improve the early ROM compared with the other two groups in TKA.

Level of Evidence: Therapeutic Level I.

Trial registration: The Chinese Clinical Trial Registry (ChiCTR1800017036). Registered on July 9, 2018.

Keywords: Total knee arthroplasty, Dexamethasones, Clinical outcomes, Randomized controlled study

\section{Background}

Total knee arthroplasty (TKA) has become a successful surgical method for the treatment of severe knee diseases [1-3]. TKA, however, involves extensive osteotomy, soft tissue release and surgical trauma, which often lead to severe postoperative inflammatory reactions [4-6]. Consequently, patients can experience severe pain in the early

\footnotetext{
* Correspondence: shenbin_1971@163.com

†Y Yuangang Wu and Xiaoxi Lu contributed equally to this work.

'Department of Orthopaedic Surgery, West China Hospital, West China Medical School, Sichuan University, Chengdu 610041, Sichuan Province, China

Full list of author information is available at the end of the article
}

postoperative period $[7,8]$, accompanied by postoperative nausea and vomiting (PONV) [9-11], and a prolonged length of stay (LOS) [12]. Pain and PONV may hinder the early recovery of TKA, resulting in patients dissatisfaction [13-16]. Therefore, it is better to improve the fast-track recovery of patients in reducing postoperative inflammation, relieving pain and preventing PONV.

Glucocorticoids, which have powerful anti-inflammatory and antiemetic effects, are widely used in perioperative management, such as abdominal [17, 18], gynaecologic [19], and TKA surgery [20-22], for reducing the postoperative inflammatory response, alleviating postoperative pain and preventing PONV. However, the most suitable protocol 
for administration and dosage remains controversial. As previously reported, glucocorticoids were given at a single and low dose, with fewer samples in most previous studies [23-25]. In addition, concerns regarding the adverse effects of glucocorticoid therapy, including infection and gastrointestinal bleeding, have potentially limited its widespread use in TKA [26]. Last, although the administration of the drug provides better pain and vomiting relief than traditional methods, many patients still suffer from it at the initial stage after surgery $[19,22,27]$.

The current study was therefore designed to compare the effectiveness and safety of multiple low doses of dexamethasone in patients following primary TKA by evaluating: (1) whether multiple low doses of dexamethasone reduce postoperative inflammatory markers and the incidence of PONV; (2) whether multiple low doses of dexamethasone relieve pain and provide an additional analgesic effect, improving the range of motion (ROM) and patient satisfaction; and (3) whether multiple low doses of dexamethasone are safe in primary TKA.

\section{Methods}

\section{Study design and patients}

This randomized controlled trial was approved by the institutional ethics committee and written informed consent was obtained from each patient. The study was registered in the Chinese Clinical Trial Registry on 09/07/ 2018 (ChiCTR1800017036). All consecutive patients with a diagnosis of end-stage osteoarthritis following primary unilateral TKA were enrolled for inclusion in the study. The exclusion criteria were as follows: rheumatoid arthritis, revision surgery, allergy to the dexamethasone and tranexamic acid, administration of the glucocorticoid 3 months before surgery, alcohol dependence, a history with thrombosis, the severe liver and kidney deficiency and body mass index (BMI) $>35 \mathrm{~kg} / \mathrm{m}^{2}$. Patients were randomly assigned to three groups containing 50 patients with a list generated by a computer, and randomization was blind and performed with the use of sealed envelopes at a ratio of 1:1:1 to be opened just prior to surgery.

Patients in the Group A was given intravenously $2 \mathrm{~mL}$ of normal saline solution $1 \mathrm{~h}$ before the surgery and repeated $6 \mathrm{~h}$ after surgery. Patients in the Group B was given intravenously $10 \mathrm{mg}$ dexamethasone $(2 \mathrm{ml}$, Tianjin Kingyork group Co., Ltd., China) $1 \mathrm{~h}$ before the surgery and repeated intravenously $2 \mathrm{~mL}$ of normal saline solution $6 \mathrm{~h}$ after surgery. Patients in the Group $\mathrm{C}$ was given intravenously $10 \mathrm{mg}$ dexamethasone solution $1 \mathrm{~h}$ before the surgery and repeated $6 \mathrm{~h}$ after surgery. To support the double-blind study, patients in group A were treated with 2 doses of a normal saline solution and patients in group B were treated also normal saline solution $6 \mathrm{~h}$ after surgery. All drugs were administered by a nurse who was not involved in the study. The patients, investigators, and statisticians were all blind during the study.

\section{Surgical technique}

All patients were performed general anesthesia, which was administered by the same anesthetists. All TKAs were performed by 1 senior orthopedic surgeon through a midline skin incision, medial parapatellar approach. All patients have used the PFC Sigma PS (DePuy Orthopedics Inc., Warsaw, IN, USA) prosthesis. All of the wound closed at about $45^{\circ}$ of knee bends. The arthrotomy closure was performed using an interrupted figure-of-eight \#1 EthibondTM (Ethicon, Somerville, NJ, USA), a subdermal closure using interrupted buried simple 2-0 Monocryl TM (Ethicon) and staples for skin closure. All patients were given intraoperatively $20 \mathrm{mg} /$ $\mathrm{kg}$ tranexamic acid (Chongqing Lummy Pharmaceutical Co., Ltd. China) $10 \mathrm{~min}$ before the skin incision, and repeated $3 \mathrm{~h}$ after surgery. No patients used the tourniquet, drainage tube, femoral nerve block and/or intravenous patient-controlled analgesia.

\section{Postoperative care}

All patients received cefuroxime $1.5 \mathrm{~g} 2 \mathrm{~h}$ before the operation to prevent infection. After the operation, the patient was transferred to the anesthesia recovery unit for $2 \mathrm{~h}$ and then sent to the inpatient ward. A cold pack was applied to the surgical site 2 days. Daily gait rehabilitation program and weight training were conducted by a physiotherapist on the first day after surgery.

All patients received the same management for pain and PONV. Multimodal oral analgesic drugs $(200 \mathrm{mg}$ q12 h celecoxib, $75 \mathrm{mg}$ q8 h pregabalin) were administered for pre-emptive analgesia 1 day before the surgery. After the surgery, the pain levels of all patients were measured using a visual analogue scale (VAS, 0 - no pain, 10 - worst imaginable pain). The routine analgesia regimen remains the same as before surgery when the VAS level of the patient was lower than 4. Oral oxycodone $(10 \mathrm{mg}$ q8 h) was used when the VAS level of the patient was between 4 and 6 , and intramuscular injection of pethidine hydrochloride $(100 \mathrm{mg})$ was used when a patient reported pain greater than 6 . The severity of nausea of all patients was measured using VAS (VAS, 0 -on nausea, 10- worst imaginable nausea). Metoclopramide $(10 \mathrm{mg})$ was injected intravenously as the first-line antiemetic rescue treatment when PONV occurred two or more times or the VAS level was greater than 4. An intramuscular injection of ondansetron $(5 \mathrm{mg})$ can be used as the second-line antiemetic rescue option when severe nausea persists after two doses of metoclopramide for a 30-min interval.

All patients were given subcutaneously low molecularweight heparin (LMWH, $0.2 \mathrm{~mL}, 2000 \mathrm{IU}$ ) at $6 \mathrm{~h}$ postoperatively, and repeated with a full dose at 24-h intervals 
(0.4 mL, $4000 \mathrm{IU})$ until discharge. After discharge, $10 \mathrm{mg}$ rivaroxaban (Xarelto, Bayer, Germany) was administered orally for 15 days to prevent thrombosis [28]. Intermittent pneumatic compression device was routinely applied on the calves of patients until walking. Doppler ultrasound examination was used assessing deep vein thrombosis (DVT) at the time of discharge and at 1, 3-month follow-up assessments, or at any time clinically suspected DVT. Pulmonary embolism (PE) was diagnosed on the basis of clinical symptoms and chest computed tomography $(\mathrm{CT})$ scans.

\section{Outcome measurements}

The outcomes were evaluated including the inflammation reaction of CRP and IL-6, pain level (VAS score) and the number of patients requiring analgesic rescue drugs (Oxycodone and Pethidine hydrochloride), the severity of nausea (VAS score), the incidence of PONV and the number of patients requiring antiemetic rescue (Metoclopramide and Ondansetron). CRP, IL-6, pain level, the severity of nausea, and PONV were routinely tested preoperatively and at 24,48 , and $72 \mathrm{~h}$ postoperatively. Nausea was defined as a subjective feeling of unpleasant related to awareness of the urge to vomit. Vomiting is the forcible discharge of stomach contents from the mouth. ROM and a six-point satisfaction questionnaire [5] was assessed at the time of discharge. The LOS and wound-related complications were recorded carefully.

\section{Statistical analysis}

The sample size of the current study was calculated, as previously described by Lunn [24], using VAS score as the primary outcome; it was determined that, for $90 \%$ power and a significance level of 0.05 , requiring 24 patients in each group. With the consideration of exclusion, we decided to include 50 patients in each group. One-way ANOVA and Tukey's post-hoc were used to compare the quantitative data, such as CRP, IL-6, pain level, the severity of nausea, and ROM. The Pearson chi-square test or Fisher exact test was used for comparing qualitative data, such as the incidence of PONV, patient satisfaction, and complications. All analyses were performed using SPSS version 22.0, significance was set at $P<0.05$.

\section{Results}

\section{Baseline characteristics}

During the recruitment period from January 2017 to October 2017, 165patients with osteoarthritis requiring unilateral primary TKA were scheduled. Among these patients, 15 of these patients were excluded for the following reasons: $6 \mathrm{pa}-$ tients with glucocorticoid 3 months before surgery, 3 had alcohol dependence, 5 declined to participate, 1 had an infection. Thus, 150 patients were eventually included in the analysis, 50 patients were randomized to each group (Fig.1).
No patients were lost during the follow-up. Table 1 summarizes the baseline characteristics of the 3 groups. There were no statistically significant differences in age, gender, BMI, American Society of Anesthesiologists, preoperative Hb, Hct, CRP, IL-6, ROM and VAS among the 3 groups of patients.

\section{Inflammation marks}

The mean CRP and IL-6 increased postoperatively in all patients after the surgery. The mean level of CRP peaked $48 \mathrm{~h}$ postoperatively among the 3 groups. It was significantly lower in Group C and Group B than Group A at 24. $(P<0.001, P<0.001), 48(P<0.001, P<0.001)$, and $72 \mathrm{~h}(P<0.001, P<0.001)$ postoperatively. The mean level of CRP in Group C was lower than Group B at $24 \mathrm{~h}$ $(P<0.001)$ postoperatively, however, it was no statistical significance at $48(P=0.081)$ and $72 \mathrm{~h}(P=0.057)$ postoperatively (Fig.2).

The mean level of IL-6 peaked in Group C and B at $48 \mathrm{~h}$ postoperatively compared with Group A at $24 \mathrm{~h}$ postoperatively. It was significantly lower in Group C and Group B than Group A at $24(P<0.001, P<0.001)$, $48(P<0.001, P<0.001)$, and $72 \mathrm{~h}(P<0.001, P<0.001)$ postoperatively. Although, the mean level of IL- 6 in Group B was slightly greater than Group $C$ at $24(P=0.133)$, $48(P=0.073)$, and $72 \mathrm{~h}(P=0.075)$ postoperatively, it was no statistical significance (Fig.3).

\section{Pain level and rescue analgesic}

The postoperative mean VAS pain score was significantly lower in Group C than in Group A at $24 \mathrm{~h}(P<0.001), 48$ $\mathrm{h}(P=0.037)$ postoperatively and compared with $\mathrm{B} 24 \mathrm{~h}$ $(P=0.030)$ postoperatively. The differences were also statistically significant between Groups B and A at $24 \mathrm{~h}$ $(P=0.012)$ postoperatively (Fig. 4$)$.

Similar to the pain level, the number of patients requiring oxycodone and pethidine hydrochloride was lower in Group $\mathrm{C}$ compared with Group A at $24 \mathrm{~h}(P<0.001, P<0.001)$ and $48 \mathrm{~h}(P=0.003, P<0.001)$ postoperatively, and it was also lower in Group B than Group A at $24 \mathrm{~h}$ postoperatively $(P=0.027, P=0.034)$. The level of pethidine hydrochloride was less in Group C than B at $24 \mathrm{~h}$ postoperatively $(P=0.003)$ (Table 2$)$.

\section{Intensity of nausea, PONV, and rescue antiemetic}

The intensity of nausea in Group $C$ was lower than Group A at $24(P<0.001), 48(P=0.005)$ and $72 \mathrm{~h}(P=0.017)$ postoperatively and compared with Group B at $24 \mathrm{~h}(P=0.027)$ postoperatively, and it was also lower in Group B than Group A at $24 \mathrm{~h}$ postoperatively $(P=0.041)$ (Table 3 ).

Similar to the intensity of nausea, the incidence of PONV was lower in Group C than Group A at $24(P=0.002), 48$ $(P=0.041)$ and $72 \mathrm{~h}(P=0.031)$ postoperatively, and there 


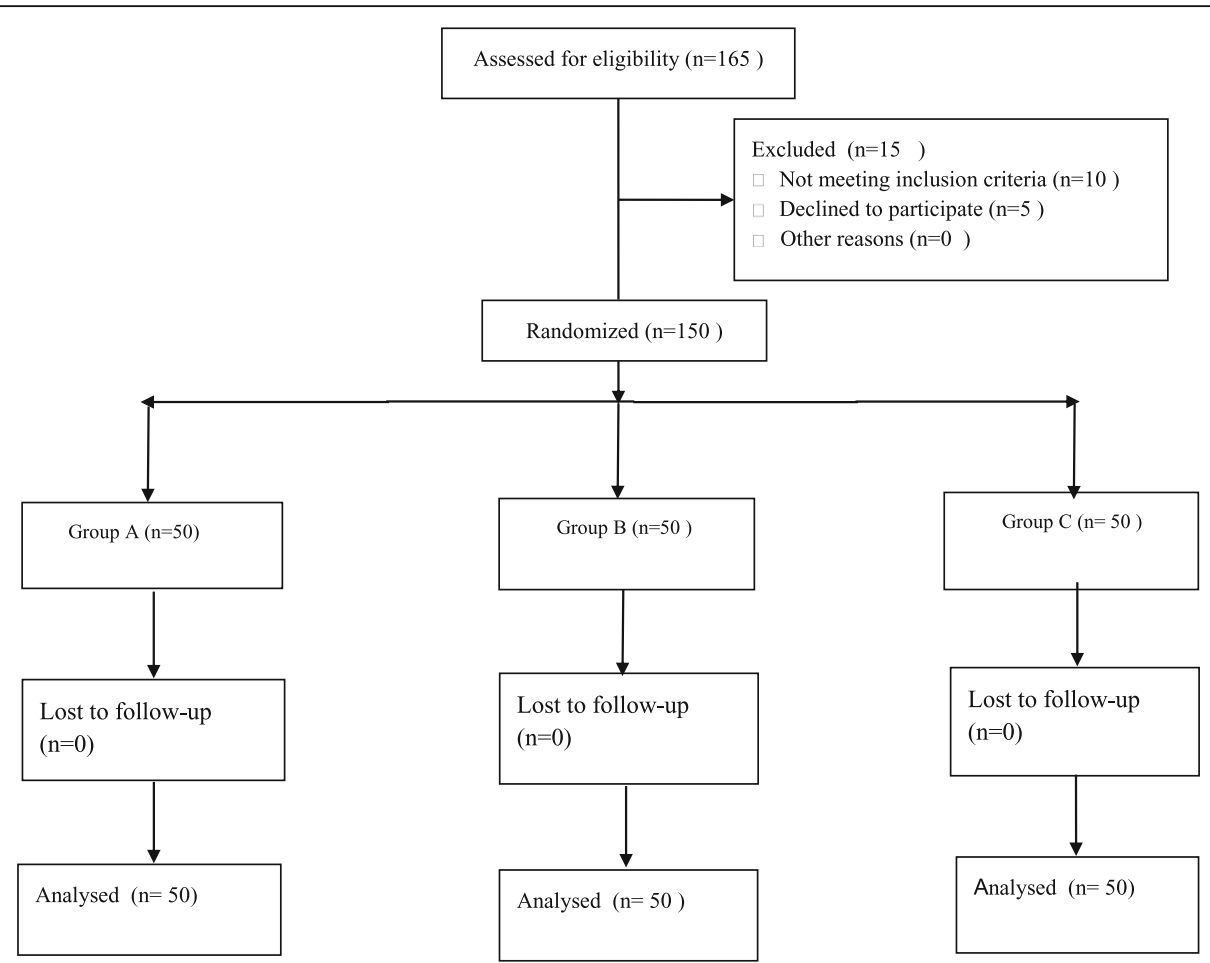

Fig. 1 A flow diagram shows the patients assessed and included among 3 groups

was also a significant difference between Groups B and A at $24 \mathrm{~h}(P=0.019)$ postoperatively (Table 3$)$.

The number of patients requiring metoclopramide was lower in Group C compared with Group A at $24(P<0.001)$, $48(P=0.025)$ and $72 \mathrm{~h}(P=0.035)$ postoperatively, and it was also lower in Group B than Group A at 24 h $(P=0.017)$ postoperatively (Table 2 ).

No three-group differences in the number of patients requiring ondansetron were found at $24(P=0.064), 48$ $(P=0.132)$ and $72 \mathrm{~h}(P=1)$ postoperatively (Table 2$)$.

Table 1 Preoperative demographics

\begin{tabular}{|c|c|c|c|c|}
\hline Variables & Group A $(n=50)$ & Group B $(n=50)$ & Group C $(n=50)$ & $P$ Value \\
\hline Age $(y)^{*}$ & $67.40 \pm 3.34$ & $66.90 \pm 4.62$ & $66.38 \pm 3.38$ & 0.414 \\
\hline $\operatorname{Gender}^{\ddagger}(\mathrm{M} / \mathrm{F})$ & $32 / 18$ & $33 / 17$ & $30 / 20$ & 0.818 \\
\hline Weight $(\mathrm{kg})^{*}$ & $65.52 \pm 4.99$ & $65.22 \pm 4.81$ & $66.38 \pm 3.84$ & 0.423 \\
\hline Hight $(\mathrm{cm})^{*}$ & $159.38 \pm 6.76$ & $158.06 \pm 5.81$ & $157.92 \pm 6.86$ & 0.465 \\
\hline BMI $\left(\mathrm{kg} / \mathrm{m}^{2}\right)^{*}$ & $25.85 \pm 2.08$ & $26.14 \pm 1.98$ & $26.70 \pm 2.08$ & 0.109 \\
\hline ASA $^{*}$ & $1.98 \pm 0.65$ & $1.94 \pm 0.65$ & $2.02 \pm 0.62$ & 0.824 \\
\hline Preop.Hb $(\mathrm{g} / \mathrm{L})^{*}$ & $13.42 \pm 0.55$ & $13.45 \pm 0.53$ & $13.39 \pm 0.56$ & 0.858 \\
\hline Preop.Hct $(L / L)^{*}$ & $39.84 \pm 1.26$ & $39.87 \pm 1.17$ & $39.74 \pm 1.25$ & 0.867 \\
\hline Preop.CRP $(\mathrm{mg} / \mathrm{L})^{*}$ & $3.23 \pm 0.96$ & $3.29 \pm 0.76$ & $3.25 \pm 0.93$ & 0.950 \\
\hline Preop.IL-6 (pg/mL) & $4.05 \pm 1.10$ & $4.15 \pm 1.15$ & $4.11 \pm 0.47$ & 0.859 \\
\hline Preop. ROM ${ }^{*}$ & $94.54 \pm 3.40$ & $93.90 \pm 3.42$ & $93.89 \pm 4.15$ & 0.594 \\
\hline Preop. VAS ${ }^{*}$ & $5.16 \pm 0.68$ & $5.32 \pm 0.82$ & $5.22 \pm 0.68$ & 0.542 \\
\hline Duration of surgery $(\mathrm{min})^{*}$ & $66.84 \pm 3.30$ & $67.92 \pm 3.30$ & $68.02 \pm 2.83$ & 0.120 \\
\hline
\end{tabular}

Abbreviations: $y$ years, $M$ male, $F$ female, $R$ right, $L$ left, $B M I$ body mass index, ASA American Society of Anesthesiologists, Preop preoperative, $H b$ hemoglobin, $H c t$ hematocrit, CRP C-reactive protein, $I L-6$ interleukin 6, ROM range of motion, VAS visual analogue scale

$P$ value indicates a significant difference among the groups

*was analyzed by the one-way ANOVA;

‡ was analyzed by the Pearson chi-square test or the Fisher exact test 


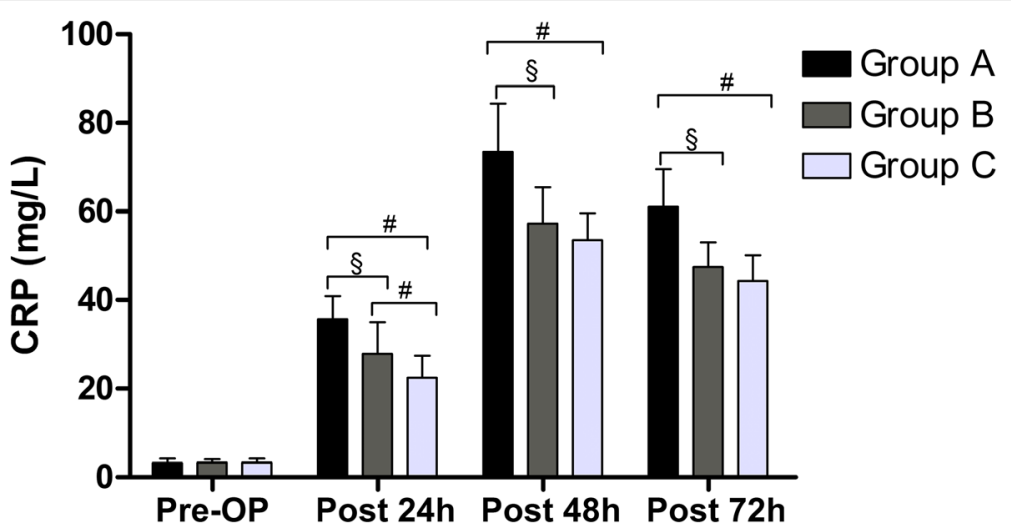

Fig. 2 The level of CRP in all groups. Pre-OP = preoperative, post= postoperative. A significant difference among the 3 groups as calculated with one-way ANOVA. \# Significantly different from the Group B. \# Significantly different from the Group C

ROM, LOS, patient satisfaction, and complications At the time of discharge, the ROM in Group $C$ was better than in Group A $(P<0.001)$ and B $(P=0.001)$, but it was no differenced in the other subgroup in another subgroup. The average LOS in Group A, B, C were $5.02 \pm 0.62,4.94 \pm 0.84$, and $4.82 \pm 0.72$ days respectively, no differences were found $(P=0.393)$. Patients in Group $C$ had significantly higher satisfaction ratings than Groups A $(P=0.002)$ and $B$ $(P=0.043)$ (Table III), no benefits in Group B relative to Group A was found $(P=0.298)$ (Table 3$)$.

No DVT and PE was found in any of the patients, however, 9 patients (group A, 3 cases, group B, 3 cases, group C, 5 cases) developed intramuscular venous thrombosis. 2 patients from Group C and 1 patients from Group B had superficial infection during the 3-month follow-up period, which was controlled by dressing change and oral antibiotics. No gastrointestinal hemorrhage occurred (Table 3).

\section{Discussion}

The most important finding of this study is that patients in Group C who were intravenously administered $10 \mathrm{mg}$ dexamethasone $1 \mathrm{~h}$ preoperatively and repeated $10 \mathrm{mg}$ at 6 postoperatively can significantly reduce the postoperative level of CRP and IL-6, decrease the incidence of PONV and receive additional analgesic and antiemetic effects, and achieve a better ROM and patient satisfaction, without increasing the risk of wound-related complications when compared with patients in Group A and B.

TKA is one of the most effective methods to treat knee diseases $[1,2]$. However, surgical trauma following TKA often results in severe postoperative inflammation, which is associated with postoperative pain and PONV [8, 9]. As a result, the fast-track treatment of the patients was hampered postoperatively. Glucocorticoids are known for their analgesic, anti-inflammatory, and anti-emetic effects, although the mechanisms are unclear. In using corticosteroids, therefore, its pharmaceutical ingredients enter the surrounding tissue and reduce the inflammatory response at the site of surgical trauma, thus providing effective pain relief. Dexamethasone is a kind of synthetic glucocorticoid with high bioavailability and long acting time. In the current study, significant increases in CRP and IL-6 levels

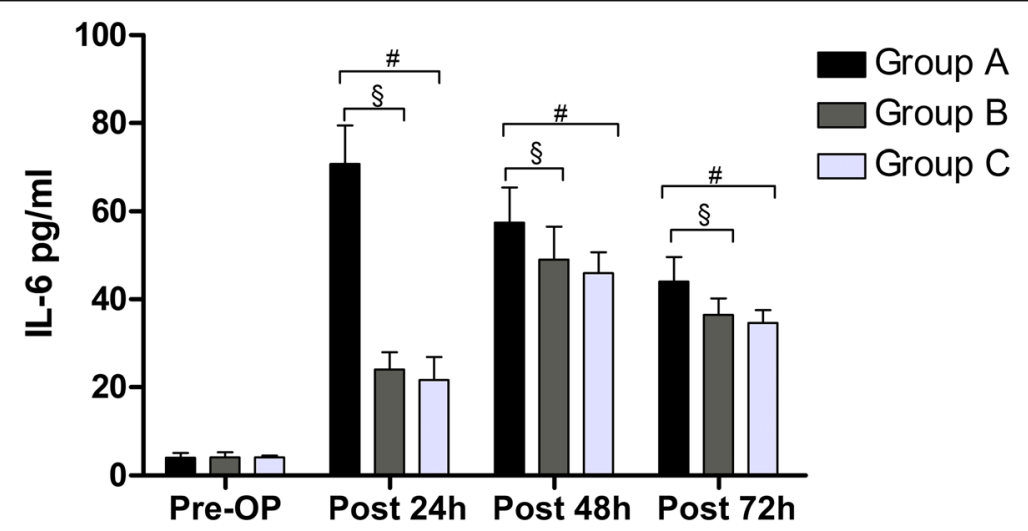

Fig. 3 The level of IL-6 in all groups. Pre-OP = preoperative, post = postoperative. A significant difference among the 3 groups as calculated with one-way ANOVA. \# Significantly different from the Group B. \# Significantly different from the Group C 


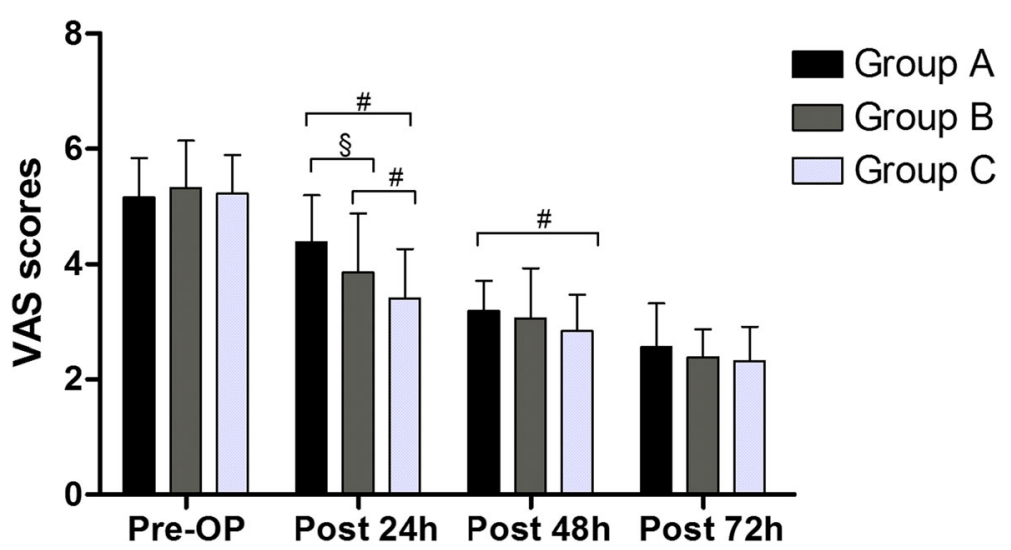

Fig. 4 The level of pain in all groups. Pre-OP= preoperative, post = postoperative. A significant difference among the 3 groups as calculated with one-way ANOVA. \# Significantly different from the Group B. \# Significantly different from the Group C

were found in the three treatment groups, however, CRP and IL-6 levels increased significantly less in Groups C and B compared with Group A at 24, 48, and $72 \mathrm{~h}$. It was also observed to be lower in Group C than in Group B. Thus, our findings suggest that intravenous dexamethasone administered $1 \mathrm{~h}$ preoperatively and repeated at $6 \mathrm{~h}$ postoperatively reduced the postoperative inflammatory response compared to Groups A and B.

Compared with the level of pain preoperatively, pain declined after TKA among the three groups. As previously reported, the analgesic effect of glucocorticoid is achieved by inhibiting phospholipase, thus blocking the pathway of cyclooxygenase and lipoxygenase in the inflammatory chain reaction [29]. At the same time, it can also inhibit the level of bradykinin [30] in tissues and the release of neuropeptides from nerve endings [31], both of which may enhance the sense of injury in inflammatory tissues and surgical wounds. An Randomized Controlled Trial (RCT) performed by Koh et al. [22] prospectively evaluated 269 TKAs randomized to receive dexamethasone (10 $\mathrm{mg}$ ) combined with ramosetron or ramosetron alone. These results suggest that patients with dexamethasone experienced lower pain and consumed fewer opioids during the 6 to $24 \mathrm{~h}$ postoperative. Similarly, another RCT study by Xu et al. [32] involving 108 TKA patients divided into 2 groups of 54 patients. The two treatment groups were either given two doses of $10 \mathrm{mg}$ IV dexamethasone or placebo, the study found that the pain at rest and walking was lower at $24 \mathrm{~h}$ postoperatively in the dexamethasone group. The results in current study echo those findings. We showed a statistically significant reduction of the VAS score of pain in Group C than Group A at 24 and

Table 2 The the number of patients of requiring rescue analgesic and antiemetic

\begin{tabular}{|c|c|c|c|c|}
\hline Variables & Group A $(n=50)$ & Group B $(n=50)$ & Group C $(n=50)$ & $P$ Value \\
\hline Oxycodone-post $24 \mathrm{~h}(\mathrm{n})^{\ddagger}$ & $28 \S \#$ & $17 \#$ & 8 & 0.001 \\
\hline Oxycodone-post $48 \mathrm{~h}(\mathrm{n})^{\ddagger}$ & $19 \#$ & 11 & 6 & 0.009 \\
\hline Oxycodone-post $72 \mathrm{~h}(\mathrm{n})^{\ddagger}$ & 8 & 5 & 3 & 0.265 \\
\hline Pethidine hydrochloride-post $24 \mathrm{~h}(\mathrm{n})^{\ddagger}$ & $22 \S \#$ & 12 & 6 & 0.001 \\
\hline Pethidine hydrochloride-post $48 \mathrm{~h}(\mathrm{n})^{\ddagger}$ & $14 \#$ & 7 & 2 & 0.004 \\
\hline Pethidine hydrochloride-post $72 \mathrm{~h}(\mathrm{n})^{\ddagger}$ & 3 & 1 & 0 & 0.166 \\
\hline Metoclopramide-post $24 \mathrm{~h}(\mathrm{n})^{\ddagger}$ & $21 \S \#$ & 10 & 7 & 0.003 \\
\hline Metoclopramide-post $48 \mathrm{~h}(\mathrm{n})^{\ddagger}$ & $12 \#$ & 7 & 3 & 0.039 \\
\hline Metoclopramide-post $72 \mathrm{~h}(\mathrm{n})^{\ddagger}$ & $6 \#$ & 2 & 0 & 0.025 \\
\hline Ondansetron-post $24 \mathrm{~h}(\mathrm{n})^{\ddagger}$ & 7 & 3 & 1 & 0.064 \\
\hline Ondansetron-post $48 \mathrm{~h}(\mathrm{n})^{\ddagger}$ & 2 & 0 & 0 & 0.132 \\
\hline Ondansetron-post $72 \mathrm{~h}(\mathrm{n})^{\ddagger}$ & 0 & 0 & 0 & 1 \\
\hline
\end{tabular}

Abbreviations: post postoperative, $h$ hours, $n$ number

₹ was analyzed by the Pearson chi-square test or the Fisher exact test

$P$ value indicates a significant difference among the groups

$\S$ Significantly different from the Group B. \# Significantly different from the Group C 
Table 3 The clinical outcomes and complications among the 3 groups

\begin{tabular}{|c|c|c|c|c|}
\hline Variables & Group A $(n=50)$ & Group B $(n=50)$ & Group C $(n=50)$ & $P$ Value \\
\hline Intensity of Nausea-post $24 \mathrm{~h}^{*}$ & $2.96 \pm 1.24 \S \#$ & $2.38 \pm 1.07 \#$ & $1.76 \pm 1.24$ & 0.001 \\
\hline Intensity of Nausea-post $48 \mathrm{~h}^{*}$ & $1.66 \pm 0.82 \#$ & $1.38 \pm 0.90$ & $1.12 \pm 0.82$ & 0.008 \\
\hline Intensity of Nausea-post $72 \mathrm{~h}^{*}$ & $1.18 \pm 0.77 \#$ & $0.94 \pm 0.73$ & $0.74 \pm 0.85$ & 0.023 \\
\hline PONV-post $24 \mathrm{~h}^{\ddagger}$ & $22 \S \#$ & 11 & 8 & 0.004 \\
\hline PONV- post $48 \mathrm{~h}^{\ddagger}$ & $14 \#$ & 8 & 5 & 0.058 \\
\hline PONV- post $72 \mathrm{~h}^{\ddagger}$ & $10 \#$ & 4 & 2 & 0.026 \\
\hline Satisfaction level $(n)^{\ddagger}$ & & & & 0.007 \\
\hline Very satisfied & $18 \#$ & $23 \#$ & 35 & \\
\hline Somewhat satisfied & 14 & 17 & 11 & \\
\hline Neither satisfied nor dissatisfied & 11 & 6 & 4 & \\
\hline Somewhat dissatisfied & 7 & 4 & 0 & \\
\hline Very dissatisfied & 0 & 0 & 0 & \\
\hline $\mathrm{ROM}^{*}$ & $99.66 \pm 2.60 \#$ & $100.70 \pm 2.37 \#$ & $102.48 \pm 1.99$ & 0.001 \\
\hline $\operatorname{LOS}\left(\right.$ days) ${ }^{*}$ & $5.02 \pm 0.62$ & $4.94 \pm 0.84$ & $4.82 \pm 0.72$ & 0.393 \\
\hline $\operatorname{DVT}(n)^{\ddagger}$ & 0 & 0 & 0 & 1 \\
\hline$P E(n)^{\ddagger}$ & 0 & 0 & 0 & 1 \\
\hline Intramuscular thrombosis $(n)^{\ddagger}$ & 3 & 3 & 5 & 0.675 \\
\hline Superficial infection $(n)^{\ddagger}$ & 0 & 1 & 2 & 0.360 \\
\hline Gastrointestinal hemorrhage $(n)^{\ddagger}$ & 0 & 0 & 0 & 1 \\
\hline
\end{tabular}

Abbreviations: Post postoperative, $h$ hours, $n$ number, PONV postoperative nausea and vomiting, ROM range of motion, LOS length of stay, DVT deep vein thrombosis, PE Pulmonary embolism

*was analyzed by the one-way ANOVA;

‡ was analyzed by the Pearson chi-square test or the Fisher exact test

$P$ value indicates a significant difference among the groups

$\S$ Significantly different from the Group B. \# Significantly different from the Group C

$48 \mathrm{~h}$ postoperatively and Group B at $24 \mathrm{~h}$ postoperatively. Furthermore, the requirements of oxycodone and pethidine hydrochloride were significantly lower in Group C.

The antiemetic effects of dexamethasone were well documented [17, 19, 22, 32] and supported in our study. However, the mechanism by which glucocorticoids relieve PONV is not fully understood. Its effect may be mediated by the inhibition of prostaglandin synthesis or the inhibition of endogenous opioid release [33]. The current study showed that two doses of dexamethasone were more effective in preventing the PONV and reducing the intensity of nausea than the single dose or without dexamethasone groups. The results are consistent with previous studies $[10,22,32]$ suggesting that dexamethasone has a better antiemetic effect. In a recent meta-analysis of 3 randomized controlled trials [34], dexamethasone not only reduces postoperative pain level and opioid consumption within $48 \mathrm{~h}$ but also reduces postoperative PONV. Although few previous studies have investigated the antiemetic efficacy of two doses of low-dose dexamethasone after TKA. The current results as well as previous studies $[10,32]$ suggest that the use of multiple low doses of dexamethasone has a stronger antiemetic effect on the early stage of PONV than a single dose of dexamethasone. The results therefore suggest that the repeated administration of dexamethasone $6 \mathrm{~h}$ postoperatively can effectively reduce the incidence of PONV. Additionally, functional outcome assessments in our study demonstrated a better ROM in Group C. The outcomes might explain the significantly higher satisfaction ratings of patients in Group $\mathrm{C}$ at the time of discharge.

However, the optimal routes and doses of dexamethasone remain controversial. A range of doses from 4 to $10 \mathrm{mg}$ in primary TKA has been established in most studies [22, 35]. Barnes et al. [36] suggested that glucocorticoids bind to intracellular glucocorticoid receptors, which are mainly mediated by the synthesis of transcriptional proteins. Therefore, the starting time of biological action is generally $1-2 \mathrm{~h}$ [29], and it was reasonable to give dexamethasone $1 \mathrm{~h}$ before the surgery so that it reached its plasma concentration at the beginning of resuscitation in this study. In addition, since early media-activated metabolic reaction occurs immediately after surgical incision [37], it is also reasonable to give dexamethasone $1 \mathrm{~h}$ before the surgery to obtain a potential therapeutic effect postoperatively. As previously reported [22, 27], patients still have to deal with pain and PONV with single-dose dexamethasone. Thus, we added 
an additional 10-mg dose of dexamethasone at $6 \mathrm{~h}$ postoperatively, assuming that it would have a meaningful clinical benefit.

Although TKA is associated with thrombosis [3, 38], and glucocorticoids are associated with wound healing and postoperative infection, previous studies using low or high doses of glucocorticoids have not shown that glucocorticoids are associated with these complications during the perioperative period [22, 32, 34]. In our study, we also found that the additional low dose of dexamethasone was given at 6 postoperatively, and no patients had an obvious adverse effect and/or complication during postoperative follow-up. It is known that synthetic glucocorticoids,such as dexamethasone, prescribed in daily care can induce hypertension. However, the exact mechanism by which glucocorticoids may induce hypertension is unclear [39]. Some evidence supports the fact that glucocorticoids may actually have nothing to do with elevated blood pressure in the first few weeks. Gabriel et al. [40] reported that $15.3 \%$ of 124 patients with rheumatoid polymyalgia prescribed glucocorticoid treatment for hypertension, and $26.3 \%$ of 57 patients who received non-steroidal anti-inflammatory drugs had hypertension. Furthermore, Fardet et al. [41] also sugessted that the increase of blood pressure during the first months of exposure to synthetic glucocorticoids seems clinically nonsignificant. At the same time, there was also no evidence that perioperative dexamethasone administration is associated with increased postoperative glucose levels $(>200 \mathrm{mg} / \mathrm{dl}$ ) or higher maximum glucose levels in total joint arthroplasty [42]. Therefore, we believe that there is evidence to support that two doses of low-dose preoperative treatment with dexamethasone are safe in TKA procedures.

This study had some limitations. The follow-up period for assessing functional outcome was $24 \mathrm{~h}, 48 \mathrm{~h}$ and $72 \mathrm{~h}$ postoperatively; therefore, this study does not show the long-term effects of dexamethasone. Second, although this study showed a lower incidence of wound-related complications, a larger sample size is required to adequately assess the significant differences in adverse events. Third, two doses of low-dose dexamethasone showed better clinical results, but the best method and dose of dexamethasone and whether a further use is needed to produce additional results remain unclear.

\section{Conclusions}

The administration of $10 \mathrm{mg}$ dexamethasone $1 \mathrm{~h}$ before the surgery, and repeated at $6 \mathrm{~h}$ postoperatively can significantly reduce the level of postoperative CRP and IL-6 and the incidence of PONV, relieve pain, achieve an additional analgesic effect, and improve the early ROM compared with the other two groups in TKA.

\section{Abbreviations}

BMI: Body mass index; CRP: C-reactive protein; DVT: Deep vein thrombosis; IL6: Interleukin 6; LOS: Length of stay; PBV: Patient's blood volume; PE: Pulmonary embolism; PONV: Postoperative nausea and vomiting; ROM: Range of motion;

TKA: Total knee arthroplasty; VAS: Visual analogue scale

\section{Acknowledgements}

The authors would like to thank Dr. Li Chen (chenli930@scu.edu.cn) from Analytical \& Testing Center Sichuan University for her help with image processing and data analysis, and I would also like to thank Dr. Shuting Li (447623681@qq.com) from Department of Ultrasonography, West China Hospital, Sichuan University, for providing diagnosis of venous thrombosis.

\section{Funding}

This study was funded by the National Natural Science Foundation of China Program (No. 81601936, No. 81672219), for providing support of design and drafted the manuscript; and it was funded by the Science and Technology Department of Sichuan Province (No. 2017FZ0056 and No. 2018HH0141), for providing support of data acquisition and language modification; and it was also funded by the Health Department of Sichuan Province (N0.18ZD016), for providing support of interpreted the data and revised the manuscript.

\section{Availability of data and materials}

All data and materials are contained within the manuscript.

\section{Authors' contributions}

$B S, Y Z$ and $Y G W$ conceived, designed and coordinated the experiments and drafted the manuscript. BS, YGW, YZ, XCB and HZX contributed to data acquisition. $Y Z, Y G W, H Z X, X X L$ and $Y M M$ analysed and interpreted the data. $X C B, H Z X, X X L$ and YMM revised the manuscript. XXL and YMM corrected language. All authors read and approved the final manuscript.

\section{Ethics approval and consent to participate}

The study was approved by the Institutional Review Board of West China Hospital (No: 201302007). All participants will be required to provide written informed consent to participate.

\section{Consent for publication}

Not applicable.

\section{Competing interests}

The authors declare that they have no competing interests.

\section{Publisher's Note}

Springer Nature remains neutral with regard to jurisdictional claims in published maps and institutional affiliations.

\section{Author details}

${ }^{1}$ Department of Orthopaedic Surgery, West China Hospital, West China Medical School, Sichuan University, Chengdu 610041, Sichuan Province, China. ${ }^{2}$ Department of Pediatrics, West China University Second Hospital, Sichuan University, Chengdu 610041, Sichuan Province, China. ${ }^{3}$ Key Laboratory of Birth Defects and Related Diseases of Women and Children (Sichuan University), Ministry of Education, Chengdu, China.

Received: 26 September 2018 Accepted: 22 November 2018

Published online: 01 December 2018

References

1. Wu Y, Zeng Y, Bao X, Xiong H, Hu Q, Li M, Shen B. Comparison of minisubvastus approach versus medial parapatellar approach in primary total knee arthroplasty. Int J Surg. 2018;57:15-21.

2. Kurtz $S$, Ong K, Lau E, Mowat F, Halpern M. Projections of primary and revision hip and knee arthroplasty in the United States from 2005 to 2030. J Bone Joint Surg Am. 2007;89:780-5.

3. Wu Y, Zeng Y, Li C, Zhong J, Hu Q, Pei F, Shen B. The effect of postoperative limb positioning on blood loss and early outcomes after primary total knee arthroplasty: a randomized controlled trial. Int Orthop. Epub 2018 Oct 23.

4. Filos KS, Lehmann KA. Current concepts and practice in postoperative pain management: need for a change? Eur Surg Res. 1999;31:97-107. 
5. Huang Z, Xie X, Li L, Huang Q, Ma J, Shen B, Kraus VB, Pei F. Intravenous and Topical tranexamic acid alone are superior to tourniquet use for primary Total knee arthroplasty: a prospective, Randomized Controlled Trial. J Bone Joint Surg Am. 2017;99:2053-61.

6. Shen $H$, Zhang N, Zhang X. Ji W. C-reactive protein levels after 4 types of arthroplasty. Acta Orthop. 2009;80:330-3.

7. Cui Z, Liu X, Teng Y, et al. The efficacy of steroid injection in total knee or hip arthroplasty. Knee Surg Sports Traumatol Arthrosc. 2015;23:2306-14.

8. Kehlet $\mathrm{H}$, Jensen TS, Woolf CJ. Persistent postsurgical pain: risk factors and prevention. Lancet. 2006;367:1618-25.

9. Chen JJ, Frame DG, White TJ. Efficacy of ondansetron and prochlorperazine for the prevention of postoperative nausea and vomiting after total hip replacement or total knee replacement procedures: a randomized, doubleblind, comparative trial. Arch Intern Med. 1998;158:2124-8.

10. Backes JR, Bentley JC, Politi JR, Chambers BT. Dexamethasone reduces length of hospitalization and improves postoperative pain and nausea after total joint arthroplasty: aprospective randomized controlled trial. J Arthroplast. 2013;28(8 Suppl):11-7.

11. Gan TJ, et al. Consensus guidelines for managing postoperative nausea and vomiting. Anesth Analg. 2003;97:62.

12. Aasvang EK, Luna IE, Kehlet $\mathrm{H}$. Challenges in postdischarge function and recovery: the case of fast-track hip and knee arthroplasty. Br J Anaesth. 2015;115:861-6.

13. Polkowski GG 2nd, Ruh EL, Barrack TN, Nunley RM, Barrack RL. Is pain and dissatisfaction after TKA related to early-grade preoperative osteoarthritis? Clin Orthop Relat Res. 2013;471:162-8.

14. Gunaratne R, Pratt DN, Banda J, Fick DP, Khan RJK, Robertson BW. Patient dissatisfaction following Total knee arthroplasty: a systematic review of the literature. J Arthroplast. 2017;32:3854-60.

15. Dorr LD, Chao L. The emotional state of the patient after total hip and knee arthroplasty. Clin Orthop Relat Res. 2007:463:7-12.

16. Myles PS, Williams DL, Hendrata M, Anderson H, Weeks AM. Patient satisfaction after anaesthesia and surgery: results of a prospective survey of 10,811 patients. Br J Anaesth. 2000;84:6-10.

17. Zaghiyan K, Melmed GY, Berel D, Ovsepyan G, Murrell Z, Fleshner P. A prospective, randomized, noninferiority trial of steroid dosing after major colorectal surgery. Ann Surg. 2014;259:32-7.

18. Srinivasa S, Kahokehr AA, Yu TC, Hill AG. Preoperative glucocorticoid use in major abdominal surgery: systematic review and meta-analysis of randomized trials. Ann Surg. 2011:254:183-91.

19. Yang XY, Xiao J, Chen YH, Wang ZT, Wang HL, He DH, Zhang J. Dexamethasone alone vs in combination with transcutaneous electrical acupoint stimulation or tropisetron for prevention of postoperative nausea and vomiting in gynaecological patients undergoing laparoscopic surgery. $\mathrm{Br} J$ Anaesth. 2015;115:883-9.

20. Luna IE, Kehlet H, Jensen CM, Christiansen TG, Lind T, Stephensen SL, Aasvang EK. The effect of preoperative intra-articular methylprednisolone on pain after TKA: a randomized double-blinded placebo controlled trial in patients with high-pain knee osteoarthritis and sensitization. J Pain. 2017;18: 1476-87.

21. Hartman J, Khanna V, Habib A, Farrokhyar F, Memon M, Adili A. Perioperative systemic glucocorticoids in total hip and knee arthroplasty: a systematic review of outcomes. J Orthop. 2017;14:294-301.

22. Koh IJ, Chang CB, Lee JH, Jeon YT, Kim TK. Preemptive low-dose dexamethasone reduces postoperative emesis and pain after TKA: a randomized controlled study. Clin Orthop Relat Res. 2013;471:3010-20.

23. Jules-Elysee KM, Lipnitsky JY, Patel N, et al. Use of low dose steroids in decreasing cytokine release during bilateral total knee replacement. Reg Anesth Pain Med. 2011;36:36-40.

24. Lunn TH, Kristensen BB, Andersen LO, et al. Effect of high-dose preoperative methylprednisolone on pain and recovery after total knee arthroplasty: a randomized, placebo-controlled trial. Br J Anaesth. 2011;106:230-8.

25. Miyagawa Y, Ejiri M, Kuzuya T, Osada T, Ishiguro N, Yamada K. Methylprednisolone reduces postoperative nausea in total knee and hip arthroplasty. J Clin Pharm Ther. 2010;35:679-84.

26. Horne G, Devane P, Davidson A, Adams K, Purdie G. The influence of steroid injections on the incidence of infection following total knee arthroplasty. N Z Med J. 2008;121:U2896.

27. Koh IJ, Chang CB, Jeon YT, Ryu JH, Kim TK. Does ramosetron reduce postoperative emesis and pain after TKA? Clin Orthop Relat Res. 2012;470: 1718-27.
28. Wu Y, Zeng Y, Hu Q, Li M, Bao X, Zhong J, Shen B. Blood loss and costeffectiveness of oral vs intravenous tranexamic acid in primary total hip arthroplasty: a randomized clinical trial. Thromb Res. 2018 Oct 6;171:143-8.

29. Sapolsky RM, Romero LM, Munck AU. How do glucocorticoids influence stress responses? Integrating permissive, suppressive, stimulatory and preparative actions. Endocr Rev. 2000;21:55-89.

30. Hargreaves KM, Costello A. Glucocorticoids suppress levels of immunoreactive bradykinin in inflamed tissue as evaluated by microdialysis probes. Clin Pharmacol Ther. 1990;48:168-78.

31. Hong D, Byers MR, Oswald RJ. Dexamethasone treatment reduces sensory neuropeptides and nerve sprouting reactions in injured teeth. Pain. 1993;55: 171-81.

32. Xu B, Ma J, Huang Q, Huang ZY, Zhang SY, Pei FX. Two doses of low-dose perioperative dexamethasone improve the clinical outcome after total knee arthroplasty: a randomized controlled study. Knee Surg Sports Traumatol Arthrosc. 2018;26:1549-56.

33. Henzi I, Walder B, Tramer MR. Dexamethasone for the prevention of postoperative nausea and vomiting: a quantitative systematic review. Anesth Analg. 2000;90:186-94.

34. Fan ZR, Ma J, Ma XL, Wang Y, Sun L, Wang Y, Dong BC. The efficacy of dexamethasone on pain and recovery after total hip arthroplasty: a systematicreview and meta-analysis of randomized controlled trials. Medicine (Baltimore). 2018;97:e0100.

35. Fujii $Y$, Nakayama M. Effects of dexamethasone in preventing postoperative emetic symptoms after total knee replacement surgery: a prospective, randomized, double-blind, vehicle-controlled trial in adult Japanese patients. Clin Ther. 2005;27:740-5.

36. Barnes PJ. Anti-inflammatory actions of glucocorticoids: molecular mechanisms. Clin Sci (Lond). 1998;94:557-72.

37. Wang JJ, Ho ST, Tzeng Jl, Tang CS. The effect of timing of dexamethasone administration on its efficacy as a prophylactic antiemetic for postoperative nausea and vomiting. Anesth Analg. 2000;91:136-9.

38. Wu Y, Yang $T$, Zeng $Y$, Si H, Cao F, Shen B. Tranexamic acid reduces blood loss and transfusion requirements in primary simultaneous bilateral total knee arthroplasty: a meta-analysis of randomized controlled trials. Blood Coagul Fibrinolysis. 2017 Oct;28(7):501-8.

39. PeppaM, KraniaM, Raptis SA. Hypertension and other morbidities with Cushing's syndrome associated with corticosteroids: a review. Integr Blood Press Control 2011:4:7-16.

40. Gabriel SE, Sunku J, Salvarani C, O'Fallon WM, Hunder GG. Adverse outcomes of antiinflammatory therapy among patients with polymyalgia rheumatica. Arthritis Rheum. 1997:40:1873-8.

41. Fardet L, Nazareth I, Petersen I. Synthetic glucocorticoids and early variations of blood pressure: a population-based cohort study. J Clin Endocrinol Metab. 2015;100(7):2777-83.

42. Nurok M, Cheng J, Romeo GR, Vecino SM, Fields KG, YaDeau JT. Dexamethasone and perioperative blood glucose in patients undergoing total joint arthroplasty: a retrospective study. J Clin Anesth. 2017;37:116-22.
Ready to submit your research? Choose BMC and benefit from:
- fast, convenient online submission
- thorough peer review by experienced researchers in your field
- rapid publication on acceptance
- support for research data, including large and complex data types
- gold Open Access which fosters wider collaboration and increased citations
- maximum visibility for your research: over $100 \mathrm{M}$ website views per year
At BMC, research is always in progress.
Learn more biomedcentral.com/submissions 